Article

\title{
Procedure to Evaluate the Impact in Distribution Single Phase Transformers Due to Insertion of New Nonlinear Load Which Changes Daily Demand Graphs
}

\author{
Jorge Enrique Carrión González ${ }^{1, *}$, Antonio Martínez García ${ }^{2}$, Alfredo del Castillo Serpa ${ }^{2}$, \\ Marianela del Cisne Carrión González ${ }^{3}$, Rodolfo Pabel Merino Vivanco ${ }^{3}$ and \\ Kelvin Armando Alulima Carrión ${ }^{1}$ \\ 1 Electromechanical Engineering Degree, Nacional University of Loja, Loja 110150, Ecuador; \\ kelvin.alulima@unl.edu.ec \\ 2 "José Antonio Echeverría", Electrical Engineering Department, Technological University of Habana La, \\ Habana 19390, Cuba; amg@electrica.cujae.edu.cu (A.M.G.); acastillo@cemat.cujae.edu.cu (A.d.C.S.) \\ 3 Electronics and Telecommunications Engineering Degree, Nacional University of Loja, Loja 110150, Ecuador; \\ marianela.carrion@unl.edu.ec (M.d.C.C.G.); rodolfo.merino@unl.edu.ec (R.P.M.V.) \\ * Correspondence: jorge.carrion.g@unl.edu.ec or jorgecarriong@yahoo.es; Tel.: +593-99-4448995
}

Received: 29 August 2019; Accepted: 14 October 2019; Published: 16 October 2019

check for updates

\begin{abstract}
Power electronic development determines the introduction of nonlinear devices in electric power systems. Introduction of nonlinear devices increase current harmonics in transmission and distribution power systems. Distribution transformers and feeders increase power losses and their nominal parameters are reduced. The present work introduces a procedure to evaluate maximum permissible load in single phase distribution transformers with the introduction of a new type of nonlinear load which changes daily demand graphs.
\end{abstract}

Keywords: current harmonics; stray losses; statistical inference; daily demand graphs

\section{Introduction and Background}

The impetuous development of power electronics has led to the introduction of "flexible alternating current transmission systems" (FACTS) in transmission networks. Household appliances and computer equipment that are based on applications of this discipline are growing in homes. Electric vehicles are being imposed over internal combustion vehicles, which implies an increase in charging stations that are also based on power electronics. The above-mentioned results in harmonic current increases in transmission and distribution networks. Harmonic currents produce additional windings heating, due to stray losses caused by Eddy currents. Stray losses determine the level of decreasing the rated current for risen harmonics, according to the standard ANSI/IEEE C.57.110 [1,2]. This situation explains the increases in temperature, above nominal values, in transformers that feed nonlinear loads, even when the fundamental load current is below its nominal value, exposing it to premature failures. The transformers, until a few years ago, were designed to operate under sinusoidal conditions at the source and/or the load, but in practice, the presence of harmonics caused by nonlinear loads, such as electronic equipment and rectifiers, is a form of current pollution that causes problems if the effective harmonics current increases above certain limits [2-4].

Additionally, the introduction of new types of nonlinear loads that modify the typical daily current demand graph complicate the evaluation of transformers heating state necessary to timely decision making. 
In recent works $[2,4,5]$, distribution single phase transformer's declassification in a peak hourly interval is evaluated based on fundamental current and its harmonics. To prevent isolation damage of single-phase transformers, a measure of fundamental currents and its harmonics in a work cycle are necessary [6-9]. Transformer load state during a work cycle can be estimated, according to the standard ANSI/IEEE C.57.110, by known harmonic effective currents, harmonic losses factors, and ambient temperature. Harmonic effective currents and harmonic losses factors are hourly random variables, which is why a deterministic calculation of transformer load state in and hourly interval or work cycle is not a reliable procedure for its evaluation.

Required measures in all distribution monophasic transformers, with the purpose of determination its loading state, is practically impossible. The present work proposes a procedure based on a representative database of transformer secondary fundamental and harmonic currents, in order to estimate hourly typical harmonic currents and harmonic loss factors graphs. With this information, single measure or estimates of the fundamental peak current permit a reliable estimation of all transformer's loading state and higher bound errors necessary to real time supervision and future secure transformer exploitation.

The present procedure is also applicable when monophasic distribution transformers feeds a new discrete number of nonlinear loads, which changes typical to daily demand graphs. In this case, new typical daily demand graphs may be determined.

\section{Materials and Methods}

Previous assumptions presuppose homogeneity throughout the analyzed period. To undertake this task, it is necessary to $[10,11]$ :

(a) Characterize the typical demand graph when different quantities of a type of polluting load are introduced.

(b) Identify average values of the harmonic losses factors in conductors during the different hours of the day $\left(F_{H L}\right)$ and in other parts of the transformer $\left(F_{H L-S T R}\right)$ and their confidence intervals.

(c) Identify the typical hourly graph of harmonics' effective current and its confidence interval when different quantities of a new type of polluting load are introduced.

(d) Estimate, with the information in subsections a-c, previous heating state of the transformer when the electric peak begins.

(e) Once the fundamental peak load and ambient temperature are known or estimated, calculate the actual heating state of the transformer so that the temperature of the hottest point does not exceed the limit temperature according to its insulation class, to contribute to timely decision making.

Additionally, it is necessary to take into account some assumptions and considerations already established, among which are:

(a) It is assumed with some foundation that all consumers of the identified population have a potential for installed equipment (not including new pollutant loads) that cause a similar behavior of current harmonics. That means that their behavior is a randomized variable with normal distribution in each hourly time interval.

(b) The influence of iron losses on the additional heating suffered by the single-phase distribution transformer is negligible.

(c) Distribution transformer heating is a slow physical phenomenon, given their high thermal inertia, which causes them to reach their highest temperature after the period of higher overload.

It is also important to estimate the value of the highest temperature that reaches the hottest point of the transformer $[7,12]$, since this is an important indicator that determines its operational life span. The value of the maximum temperature reached by the transformer depends not only on the overload to which it is subjected, but also on its previous heating and ambient temperature, which is clear in 
the IEEE C57.110 $[1,3,13,14]$, where it is advisable to consider as a state prior to the overload, the one corresponding to 12 hours before this overload takes place.

Heating is due to the heat generated internally for two fundamental causes: losses in iron and losses due to Joule and stray effect in windings and other parts of transformers $[6,14,15]$.

The losses due to the Joule and stray effect are much greater than those in iron, so heating will depend fundamentally on them. Additionally, iron losses variations with frequency are negligible, not with the losses caused by current harmonics.

In the vast majority of international works, $[8,10,11,14]$ the transformers' heating state is calculated only in one hour, given the connected load and the known harmonic composition of the current. In analyzed works, transformer heating is considered a deterministic variable and its evaluation is not reliable. This paper is based on a procedure to solve the aforementioned problem, where transformer heating is considered a random variable and transformer heating can be evaluated with a minimum number of measurements, which is summarized in a synthesized way below.

\subsection{Proposed Procedure}

1. Characterize the population.

2. Select a representative sample.

3. Obtain the typical daily current demand graph in transformers, due to the inclusion of a new type of polluting load.

4. Identify homogeneous groups of transformers (by capacity and number of users with polluting loads) considering the effective harmonics current as a normally distributed random variable.

5. Characterize harmonic losses factors $F_{H L}$ and $F_{H L-S T R}$ according to the groups determined in step 4.

6. Identify an appropriate variable of loading state of each transformer (intensity of fundamental current in the peak), that can be measured or estimated to decode to natural values the typical graphs of fundamental and harmonics effective current corresponding to analyzed transformer and perform the calculation of its equivalent heating state. Estimate results' confidence intervals.

\subsection{Proposed Procedure Description}

Step 1: Distribution subsystem characterization related with those transformers that have associated new types of polluting loads. This characterization corresponds to the total population of transformers that have consumers associated with this type of load. This step concludes with Table 1.

Table 1. Subsystem characterization with a new type of polluting load.

\begin{tabular}{ccccccc}
\hline \multirow{2}{*}{$\begin{array}{c}\text { Transformers } \\
\text { Capacity (kVA) }\end{array}$} & \multirow{2}{*}{$\begin{array}{c}\text { Transformers } \\
\text { Quantity }\end{array}$} & \multicolumn{5}{c}{ Quantity of the New Type of Pollutant Load } \\
\cline { 3 - 6 } & & With $\mathbf{1}$ & With 2 & With 3 & With & With r \\
\hline 1 & $\mathrm{~T}_{1}$ & $\mathrm{~N}_{1}{ }^{1}$ & $\mathrm{~N}_{1}{ }^{2}$ & $\mathrm{~N}_{1}{ }^{3}$ & $\ldots$ & $\mathrm{N}_{1}{ }^{\mathrm{r}}$ \\
$\mathrm{k}$ & $\mathrm{T}_{\mathrm{K}}$ & $\mathrm{N}_{\mathrm{K}}{ }^{1}$ & $\mathrm{~N}_{\mathrm{K}}{ }^{2}$ & $\mathrm{~N}_{\mathrm{K}}{ }^{3}$ & $\ldots$ & $\mathrm{N}_{\mathrm{K}}{ }^{\mathrm{n}}$ \\
\hline
\end{tabular}

Step 2: Selection of a stratified sample that is representative of the total population of transformers with this type of load, with the aim of obtaining information from records and/or taking measurements considering the harmonic composition of the current intensity. The sample is considered randomly. Measurements are carried out, and then it will be necessary to verify compliance with the assumptions of the random variables considered (effective intensity of harmonics current (Iefh) in p.u., and harmonic factors $\left(F_{H L}\right.$ and $\left.F_{H L-S T R}\right)$ regarding their normality. This step concludes with Table 2. 
Table 2. Representative sample of the total population of transformers with new types of pollutant loads.

\begin{tabular}{ccccccc}
\hline \multirow{2}{*}{$\begin{array}{c}\text { Transformers } \\
\text { Capacity (kVA) }\end{array}$} & \multirow{2}{*}{$\begin{array}{c}\text { Transformers } \\
\text { Quantity }\end{array}$} & \multicolumn{4}{c}{ Amount of Pollutant Loads Associated with Each Transformer } \\
\cline { 3 - 6 } & & With 1 & With 2 & With 3 & With & More than 3 \\
\hline 1 & $\mathrm{~T}_{\mathrm{M}}{ }^{1}$ & $\mathrm{~N}_{\mathrm{M} 1}{ }^{1}$ & $\mathrm{~N}_{\mathrm{M} 1}{ }^{2}$ & $\mathrm{~N}_{\mathrm{M} 1}{ }^{3}$ & $\ldots$ & $\mathrm{N}_{\mathrm{M} 1}{ }^{4}$ \\
$\mathrm{k}$ & $\mathrm{T}_{\mathrm{M}}{ }^{\mathrm{K}}$ & $\mathrm{N}_{\mathrm{MK}}{ }^{1}$ & $\mathrm{~N}_{\mathrm{MK}}{ }^{2}$ & $\mathrm{~N}_{\mathrm{MK}}{ }^{3}$ & $\ldots$ & $\mathrm{N}_{\mathrm{MK}}{ }^{4}$ \\
\hline
\end{tabular}

Step 3: Analyze, according to fundamental current intensity, the base days for obtaining a characteristic daily current demand. The hourly graphs of the fundamental current component are constructed per unit of the days of the week, based on measurements of all the transformers of the sample. The base in each day corresponds to each day's highest fundamental effective current intensity, because what matters is the shape of the daily demand graph. Compare the obtained graphs and verify the random hourly behavior (if necessary) and select the most representative day or days in the transformer heating. These selected days are used to obtain the desired characteristic day.

Step 4: Homogeneous groups for the base day or days obtained from the previous step (classes) are identified, to obtain typical average values of harmonics effective current curves. In this case, it is necessary to verify that the groups comply with the normal distribution law at each time interval.

Step 5: Evaluate for the base day or days obtained from step 4, average harmonic factors $F_{H L}$ and $F_{H L-S T R}$ in each hourly interval for each homogeneous group (classes). In this case it is necessary to verify that the groups comply in each hourly interval with the normal distribution law. At the end of this, the information of the hourly average harmonics' effective currents and harmonics' factors $F_{H L}$ and $F_{H L-S T R}$ for each selected class are obtained.

Step 6: For each transformer identify, a suitable value to decode the fundamental and harmonics' effective current intensity to natural values. With the results of the previous step, the database for heating state calculation of all transformer groups is ready. Note that each transformer is associated with only one grouping or class.

\section{Results}

As of 2010, the Ministry of Energy of Ecuador has implemented a massive replacement plan for gas cooking with induction cookers. The average demand per user of this type of cooker has been estimated at $2.4 \mathrm{~kW}[16,17]$. This decision causes important changes in the typical demand graph for residential consumers in the hours of breakfast, lunch, and dinner, as well as the increase in current harmonics circulation in transformers and distribution feeders.

To apply the proposed procedure in this case, there is information of measurements in the secondary of the transformers, provided by the E.E.R.S.S.A. (Southern Regional Electric Company S.A.), of the electrical parameters of the single-phase transformers of Loja City, in 2013, 2014, and 2015. The measurements were executed every $10 \mathrm{~min}$, for one week. Measurements include fundamental current and harmonics up to harmonic 40 .

\subsection{Application of the Procedure to the Case of Loja City, Ecuador}

Step 1: This characterization corresponds to the total population of transformers that have consumers associated with induction cookers. The information is sorted according to Table 3 from the database processing. 
Table 3. Number of cookers per transformer capacity.

\begin{tabular}{cccccc}
\hline \multirow{2}{*}{$\begin{array}{c}\text { Transformers } \\
\text { Capacity (kVA) }\end{array}$} & $\begin{array}{c}\text { Transformers } \\
\text { Quantity }\end{array}$ & \multicolumn{4}{c}{ Number of Cookers per Transformer } \\
\cline { 3 - 6 } & & With 1 & With 2 & With 3 & More than 3 \\
\hline 10 & 30 & 20 & 10 & 0 & 0 \\
15 & 32 & 18 & 10 & 2 & 2 \\
25 & 90 & 40 & 22 & 15 & 13 \\
37.5 & 45 & 18 & 9 & 13 & 5 \\
\hline
\end{tabular}

Step 2: From the previous characterization, a representative sample of transformers with induction cookers is selected (see Table 4).

Table 4. Transformers sample with induction cookers.

\begin{tabular}{cccccc}
\hline \multirow{2}{*}{$\begin{array}{c}\text { Transformers } \\
\text { Capacity (kVA) }\end{array}$} & $\begin{array}{c}\text { Transformers } \\
\text { Quantity }\end{array}$ & \multicolumn{4}{c}{ Number of Cookers per Transformer } \\
\cline { 3 - 5 } & & With 1 & With 2 & With 3 & More than 3 \\
\hline 10 & 20 & 15 & 5 & 0 & 0 \\
15 & 20 & 11 & 5 & 2 & 2 \\
25 & 78 & 34 & 16 & 15 & 13 \\
37.5 & 34 & 14 & 5 & 10 & 5 \\
\hline
\end{tabular}

Step 3: Fundamental load current behavior of each transformer capacity in the week was analyzed in order to obtain the base days required to calculate the characteristic day in the two phases of the transformer. Phases A and B are considered as the terminals of the secondary winding with central tap (Figure 1). In the analyzed case, there are no substantial differences in consumption in the winter and summer months, only slightly lower ambient temperatures in the first case, that is why the used database was for the entire year. The simple inspection method is used as an initial variant to identify potential groupings of days with respect to the average intensity during the day. Of course, this analysis is carried out in the two phases of the transformer independently.

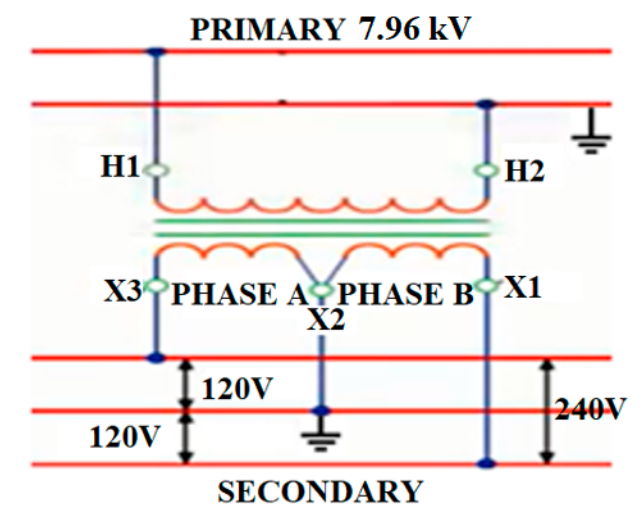

Figure 1. Single-phase transformer with central tap grounded.

The hourly demand graphs of the fundamental current intensity are constructed per unit with respect to the maximum of the corresponding day, based on the measurements provided by the E.E.R.S.S.A. The results are presented in Figure 2. 

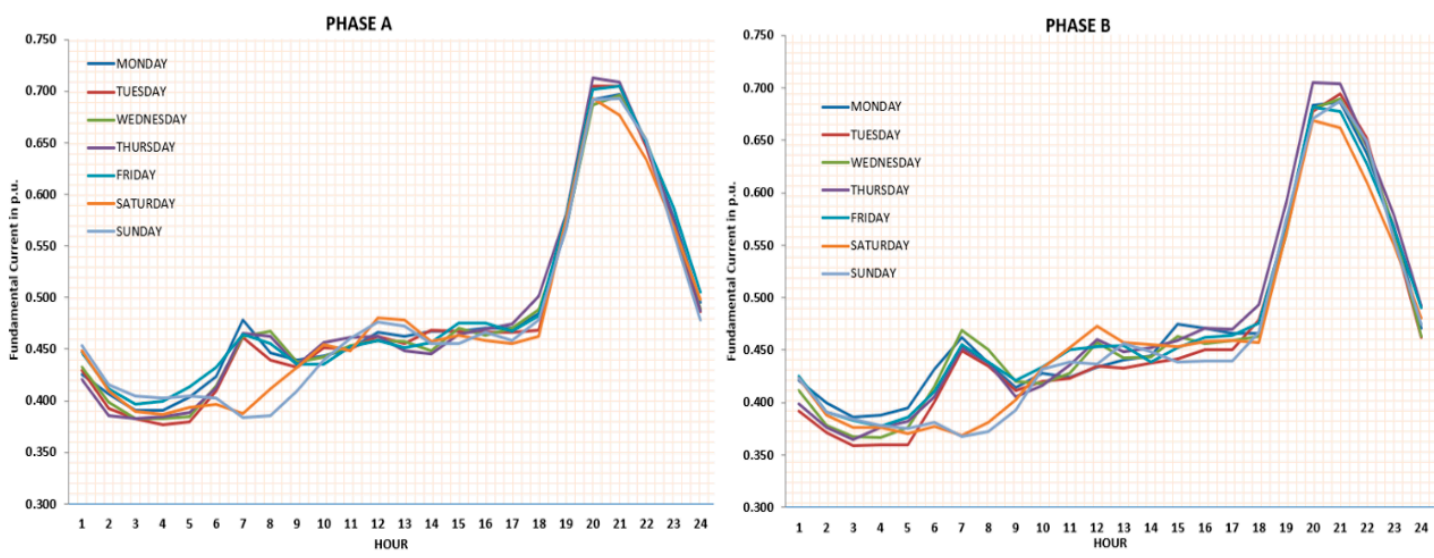

Figure 2. Hourly demand graphs of the fundamental effective currents.

Comparing the graphs, two potential groupings are evident. That is, the group from Monday to Friday and the group from Saturday to Sunday. Hypothesis tests were carried out with a significance level of 0.05 , verifying that the aforementioned groups are different, and weekdays can be considered as a homogeneous group $[9,18]$.

According to the statistical analysis carried out, it is concluded that the average demand on weekends are lower than the average demand from Monday to Friday, so the worst days for transformer heating are the days during the week. These average values during the week from Monday to Friday will be considered to evaluate transformer heating, since it is additionally known that the daily peak values, to express the demand in per unit, are kept lower on weekends than on weekdays.

Step 4: When the same data is used by grouping all transformers with any number of cookers to calculate the typical daily demand graph of harmonics effective current, based on the maximum value of the fundamental component in each day, very similar results are obtained in the shape of the curve, with slightly higher values as shown in Figure 3. However, when the compliance with the normal distribution law is checked in each time hourly interval, it is not met, so in this case a new grouping by capacity with the same number of cookers was investigated.
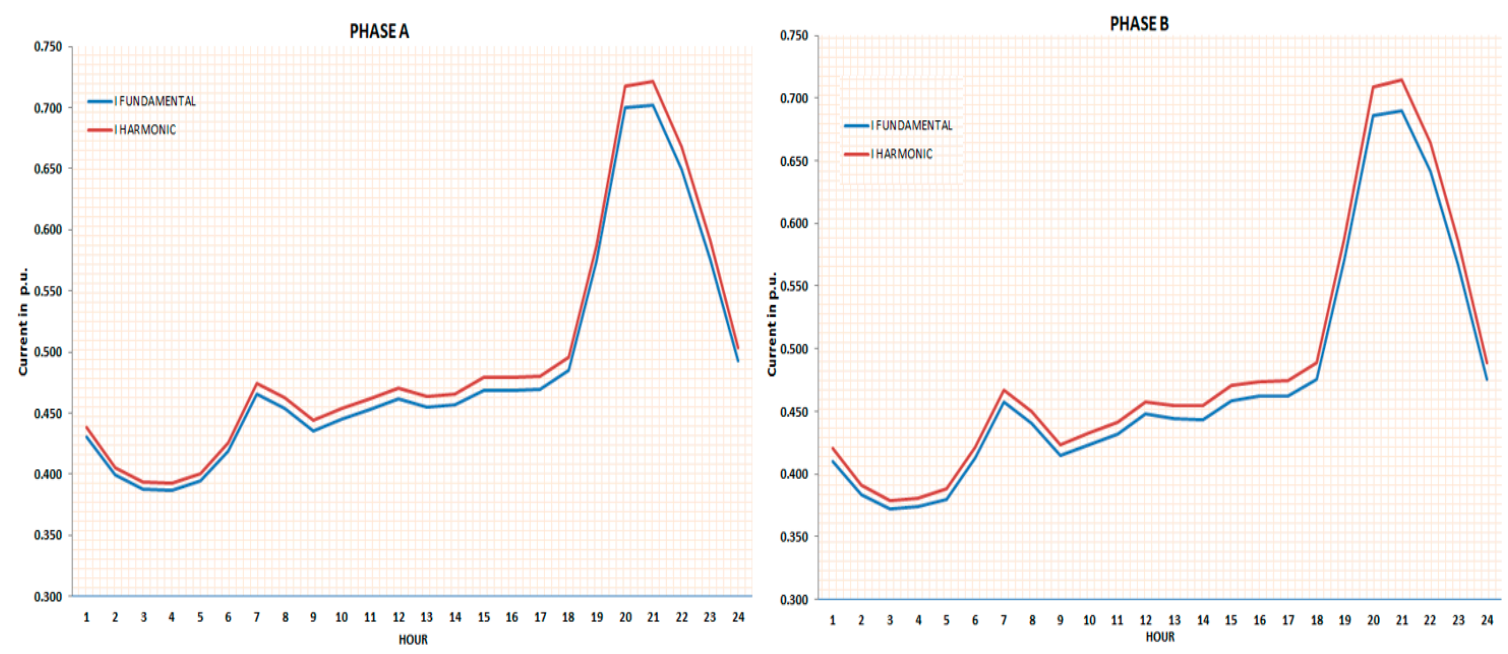

Figure 3. Typical graphs of fundamental and harmonics effective current. Phase A and B in p.u.

The results obtained for the $25 \mathrm{kVA}$ transformers with a different number of cookers in both phases are shown in Figure 4. 

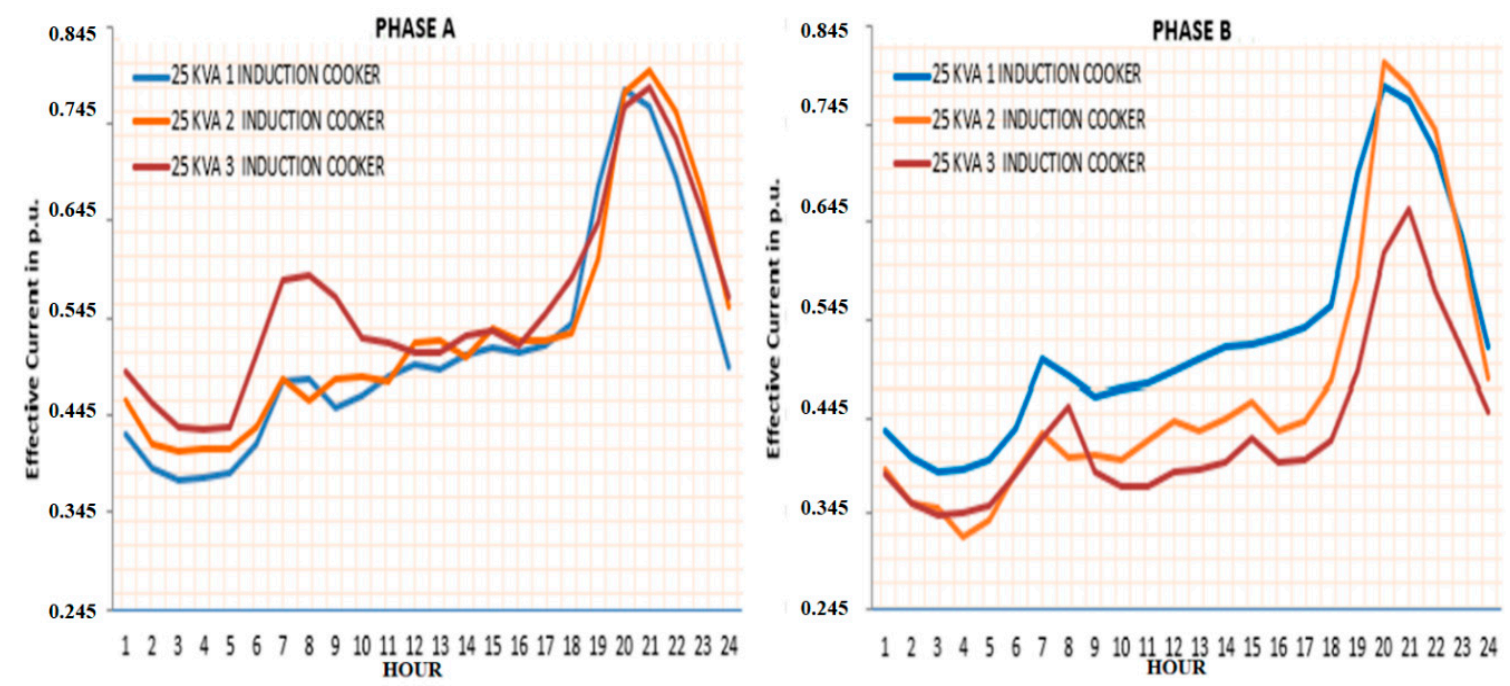

Figure 4. Typical graphs of effective harmonics currents in $25 \mathrm{kVA}$ transformers with different numbers of induction cookers.

Next, each grouping at all time intervals and for all capacities was checked, as was compliance with the normal distribution law for effective harmonics current. The goodness of fit tests used to check normality were Kolmogorov-Smirnov, Chi square, and Anderson Darling with a P value greater than 0.1 . The results were positive in all cases $[1,13,18,19]$.

Step 5: The factors $F_{H L}$ (harmonic loss factor for Eddy current losses) and $F_{H L-S T R}$ (harmonic loss factor for other stray losses) are calculated in each hour [1,14,20], for each phase, of each group (Figure 5), and the similarity tests of average values and normality were carried out at all time intervals of the groupings made in the previous step using the same goodness fit test with the same value of $\mathrm{P}$, with positive results $[1,9,18]$. High harmonic loss factor values at time intervals when induction cookers are not used is evidence that harmonic contamination is fundamentally determined by other residential equipment.

Step 6: In this step, the transformers' fundamental currents intensity must be decoded to find physical values in per unit with respect to the nominal values of the transformer.

Knowing the typical fundamental daily current demand graph and the peak current demand, it is always possible to estimate the rest of the values for the different hours of the day.

The same happens with the typical graphs of effective harmonics current that was calculated on the same basis as the fundamental one, so at any time considered it is possible to know the relationship between these two values and their real values from the measurement or estimation of the fundamental peak current intensity. After this step, it is possible to perform the calculations for any specific case. 

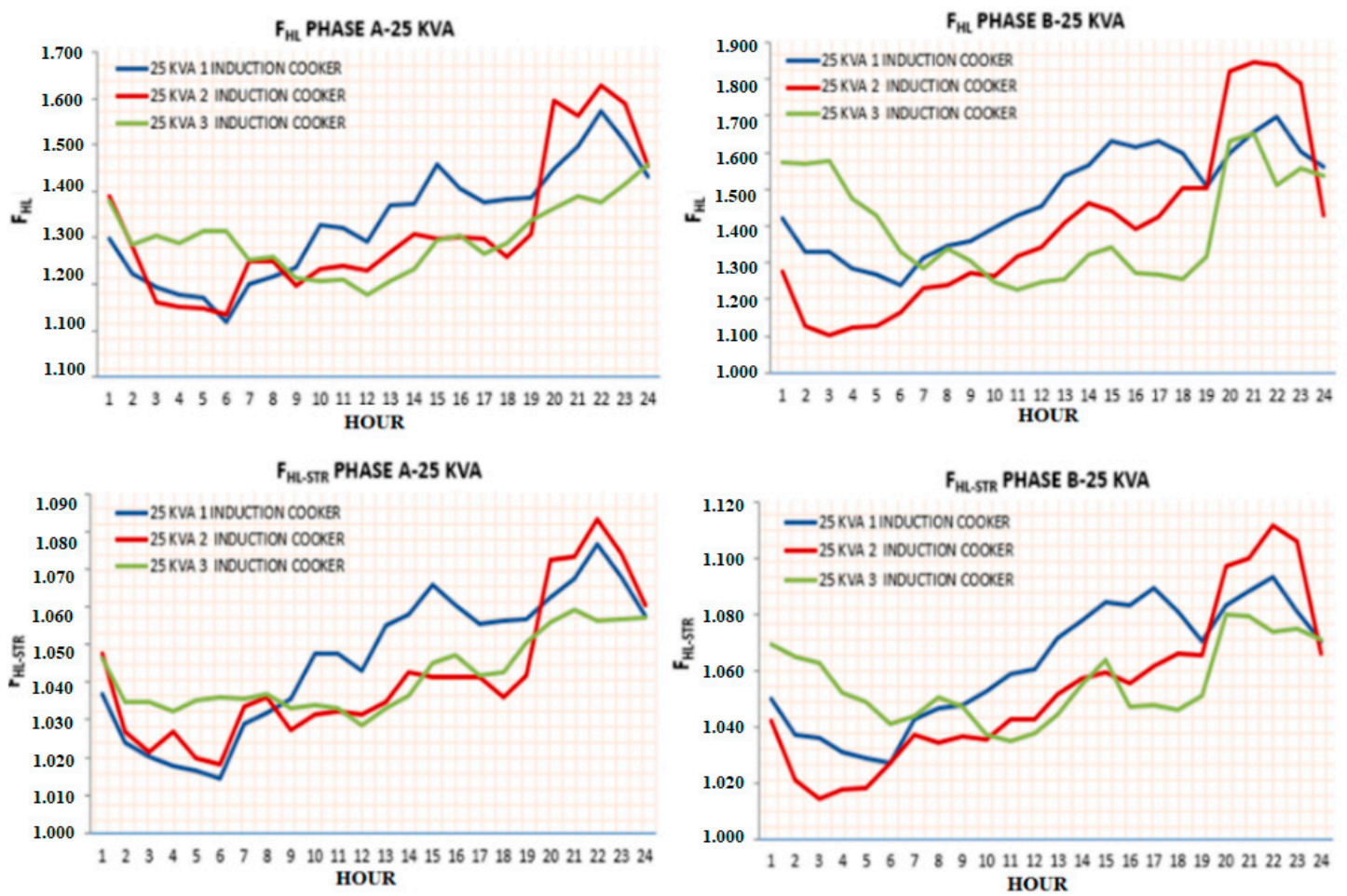

Figure 5. Typical values of $F_{H L}$ and $F_{H L-S T R}$ factors for different number of induction cookers, phases A, B.

\subsection{Calculations for a Specific Case of a $25 \mathrm{kVA}$ Transformer}

A $25 \mathrm{kVA}$ transformer with one cooker in the interval 19H00 to $20 \mathrm{H} 00$ was analyzed. The characteristic values of transformer losses in per unit (referred to as $P_{D C}$ ) are presented in Table 5.

Table 5. Nominal losses in $25 \mathrm{kVA}$, INATRA transformers.

\begin{tabular}{|c|c|c|c|c|c|c|}
\hline \multicolumn{7}{|c|}{ Nominal Loss Values For 25 kVA Transformers } \\
\hline Capacity (kVA) & PDC (W) & PEC-R (W) & POSL-R (W) & PLL-R (p.u.) & PEC-R (p.u.) & POSL-R (p.u.) \\
\hline 25 & 272.153 & 5.559 & 11.287 & 1.062 & 0.0204 & 0.0415 \\
\hline
\end{tabular}

Where:

PLL-R: Nominal copper losses at $60 \mathrm{~Hz}$.

PEC-R: Losses due to eddy $60 \mathrm{~Hz}$ currents in conductors.

POSL-R: Losses due to $60 \mathrm{~Hz}$ current in other parts of the transformer.

PDC: Nominal copper losses.

If the fundamental current intensity in phases $\mathrm{A}$ and $\mathrm{B}$ in the secondary $I_{f A}$ and $I_{f B}$, are measured in p.u. referred to the nominal transformer current in the time interval considered, it is possible to estimate:

- From the typical current curves shown in Figure 4, the average values of the harmonic effective current intensities of both phases: $I_{e f h A}$ and $I_{e f h B}$ and their confidence intervals in $p . u$. referred to the transformer nominal current.

- The mean values of the stray loss factors $F_{H L A}, F_{H L B}, F_{H L-S T R A}$ and $F_{H L-S T R B}$ of phases A and B, and their confidence intervals calculated in step 5 . 
With this information using Equation (1) derived from the ANSI/IEEE C.57.110 standard, the maximum fundamental current $\left(I_{\max }\right)$ at which the transformer can be loaded is calculated, so that its heating state is equivalent to the real one with harmonics.

$$
I_{\max }=\sqrt{\frac{\left(\frac{I^{2}{ }_{f h A}+I^{2} f h B}{2}\right)\left(P_{L L-R}\right)}{\left(\frac{I^{2}{ }_{e f h A}\left(1+\left(\left(F_{H L A} \cdot P_{E C-R}\right)+\left(F_{H L-S T R A} \cdot P_{O S L-R}\right)\right)\right)+I^{2}{ }_{e f h B}\left(1+\left(\left(F_{H L B} \cdot P_{E C-R}\right)+\left(F H L_{S T R B} \cdot P_{O S L-R}\right)\right)\right)}{2}\right)}}
$$

Considering the three variables in Equation (1) $\left(F_{H L}, F_{H L-S T R}\right.$ and $\left.I_{e f}\right)$ not dependents, it is possible to calculate the upper bound error of $I_{\max }$ calculation, using Equation (1) as:

$$
\begin{aligned}
& \Delta I_{\text {maxef }}=-0.5 \frac{\frac{I^{2} \text { fhA }+1^{2} \text { fhB }}{2} \cdot\left(\frac{I_{f A}^{2}+I^{2} f B}{2} \cdot P_{L L-R}\right)^{0.5} \cdot P_{E C-R}}{\left(\left(\frac{1_{e f h A}^{2}\left(1+\left(\left(F_{H L A} \cdot P_{E C-R}\right)+\left(F_{H L-S T R A} \cdot P_{O S L}-R\right)\right)+I^{2}{ }_{e f h B}\left(1+\left(\left(F_{H L B} \cdot P_{E C-R}\right)+\left(F_{H L-S T R B} \cdot P_{O S L-R}\right)\right)\right)\right.}{2}\right)\right)^{1.5}} \Delta F_{H L} \\
& -\frac{0.5 \cdot \frac{I_{f h A}^{2}+I_{f h B}^{2}}{2} \cdot\left(\frac{I_{f A}^{2}+I^{2}{ }_{f B}}{2} \cdot P_{L L-R}\right)^{0.5} \cdot P_{O S L-R}}{\left(\left(\frac{I^{2}{ }_{e f h A}\left(1+\left(\left(F_{H L A} \cdot P_{E C-R}\right)+\left(F_{H L-S T R A} \cdot P_{O S L-R}\right)\right)\right)+I^{2}{ }_{e f h B}\left(1+\left(\left(F_{H L B} \cdot P_{E C-R}\right)+\left(F_{H L-S T R B} \cdot P_{O S L-R}\right)\right)\right)}{2}\right)\right)^{1.5}} \Delta F_{H L-S T R} \\
& -0.5 \cdot \frac{\left(\frac{I^{2} f A+I^{2} f B}{2} \cdot P_{L L-R}\right)^{0.5} \cdot I_{e f h A}\left(1+\left(\left(F_{H L A} \cdot P_{E C-R}\right)+\left(F_{H L-S T R A} \cdot P_{O S L-R}\right)\right)\right)+I_{e f h B}\left(1+\left(\left(F_{H L B} \cdot P_{E C-R}\right)+\left(F_{H L-S T R B} \cdot P_{O S L-R}\right)\right)\right)}{\left(\left(\frac{1_{e f h A}{ }_{e}\left(1+\left(\left(F_{H L A} \cdot P_{E C-R}\right)+\left(F_{H L-S T R A} \cdot P_{O S L-R}\right)\right)\right)+I_{e}^{2}{ }_{e f h B}\left(1+\left(\left(F_{H L B} \cdot P_{E C-R}\right)+\left(F_{H L-S T R B} \cdot P_{O S L-R}\right)\right)\right)}{2}\right)\right)^{1.5}} \Delta I e f
\end{aligned}
$$

Error upper level was ensured by taking in Equation (2) the highest values of $\Delta F_{H L}, \Delta F_{H L-S T R}$ and $\Delta I e f$ of phases $\mathrm{A}$ and $\mathrm{B}$, calculated with a $95 \%$ confidence level. Equation (2) is obtained by differentiating Equation (1). Evaluating the heating state in p.u. with respect to nominal conditions in the interval $19 \mathrm{H} 00$ to $20 \mathrm{H} 00\left(P_{\text {LLTh-Peak }}\right)$, using Equation (3), for a $25 \mathrm{kVA}$ transformer with one induction cooker of Chontacruz feeder in Loja, which has average pick demand values: IfA $=0.622$ p.u., IfB $=0.63$ p.u., and Iefh $\mathrm{A}=0.634$ p.u., IefhB $=0.65$ p.u., results in:

$$
\begin{gathered}
P_{L L T h-\text { Peak }}=I^{2}{ }_{\text {efhA }}\left(\left(1+\left(F_{H L A} \cdot P_{E C-R}\right)+\left(F_{H L-S T R A} \cdot P_{O S L-R}\right)\right)\right)+I^{2}{ }_{e f h B}\left(\left(1+\left(F_{H L B} \cdot P_{E C-R}\right)+\left(F_{H L-S T R B} \cdot P_{O S L-R}\right)\right)\right) \\
P_{\text {LLTh-Peak }}=0.441 p . u .
\end{gathered}
$$

This represents $5.8 \%$ more losses due to harmonic currents, or equivalent to the fundamental current intensity of the transformer being $2.86 \%$ higher. From Equations (1) and (2) for these loading conditions:

$$
I_{\text {maxef }}=I_{\max } \pm \Delta I_{\text {maxef }}=0.971 \pm 0.009 p . u .
$$

Based on upper results, $25 \mathrm{kVA}$ transformers with one induction cooker for the analyzed peak demand lose almost $3 \%$ of their capacity. Calculation confidence level is $95 \%$.

\subsection{Transformer Heating Estimation in a Load Cycle}

The objective of the developed procedure is the evaluation of transformers heating during a load cycle, not transformer nominal declassification in a certain time interval. For this, it is not necessary to use the expression that allows declassification evaluation (1) due to current harmonics, but it is required estimation of the previous heating before the peak, and with this value and the heating during the peak, evaluate if the transformer can reach temperatures at the hottest point above what allows its thermal insulation. The preheating can be estimated as:

$$
P_{L L T h-\text { Previous }}=\sum_{i=1}^{14}\left(\frac{I_{e f h A}^{2}\left(\left(1+\left(F_{H L A} \cdot P_{E C-R}\right)+\left(F_{H L-S T R A} \cdot P_{O S L-R}\right)\right)\right)+I^{2}{ }_{e f h B}\left(\left(1+\left(F_{H L B} \cdot P_{E C-R}\right)+\left(F_{H L-S T R B} \cdot P_{O S L-R}\right)\right)\right)}{(2 \cdot N)}\right)
$$


where:

$I_{e f h A i} . I_{e f h B i}$ : Effective harmonics currents in phases A and B in the time interval $i$.

$F_{H L A i}, F_{H L-S T R A i}, F_{H L-S T R B i}, F_{H L B i}:$ Harmonic loss factors of phases A and B in the time interval $i$. $N$ : is the number of previous time intervals considered.

In this case, $14 \mathrm{~h}$ were taken to account for previous heating due to the use of induction cookers for breakfast. During the peak, transformer heating state was estimated with expressions similar to the previous ones, but only averaging the number of hours the peak occurs.

Considering the previous state of heating before the peak and during the peak and the ambient temperature, it is possible to determine using the information in Table 6 [14,20-22] if that overload is less than the maximum that the transformer can withstand without exceeding the temperature at the hottest point the maximum allowed.

Table 6. Allowable peak overloads to select the capacity of oil-cooled transformers.

\begin{tabular}{c} 
Allowable Peak Overloads to Select the Capacity of the Oil-Cooled Transformers, Equivalent Load in \\
Percentage of the Nominal. \\
\hline \multirow{2}{*}{$\begin{array}{c}\text { Peak } \\
\text { period }\end{array}$} \\
\cline { 2 - 9 }
\end{tabular}

Source: Distribution Transformers. Dr. Héctor Silvio Llamo Laborí.

The first column of Table 6 indicates the number of hours the peak lasted. In the rest of the columns: in the first row, the percentage of load prior to the transformer peak, in the second row, the average ambient temperature at analyzed heating time interval, and the rest of the rows relates to the overload values to which the transformer can be subjected during the peak period without any danger of a decrease in its operational life span. Under specific manufacturer's information it is convenient to carry out calculations based on that information and not from Table 6.

\subsection{Calculation of the $25 \mathrm{kVA}$ Transformer Heating State with One Cooker in a Load Cycle}

If the same $25 \mathrm{kVA}$ transformer is considered with one induction cooker in the Chontacruz feeder in Loja City with known typical fundamental and harmonics standardized current demand graphs in both phases (Shown in Figure 6a for phase A) and its corresponding decoded graphs (Shown in Figure $6 \mathrm{~b}$ for phase $\mathrm{A}$ ), it is possible by applying Equation (4), in the $14 \mathrm{~h}$ prior to the peak, to determine the transformer heating state prior to the period of greatest demand. By proceeding in a similar manner with the three hours that the peak lasts in Equation (5), the heating state to which the transformer is subjected in this period can be estimated. If the proposed procedure is applied, the following results are reached:

$$
\begin{gathered}
P_{\text {LLTh-Prior }}=0.276 p . u . \\
P_{\text {LTh-Peak }}=\sum_{i=1}^{3}\left(\frac{I_{\text {efhA }}^{2}\left(\left(1+\left(F_{H L A} \cdot P_{E C-R}\right)+\left(F_{H L-S T R A} \cdot P_{O S L-R}\right)\right)\right)+I_{\text {efhB }}^{2}\left(\left(1+\left(F_{H L B} \cdot P_{E C-R}\right)+\left(F_{H L-S T R B} \cdot P_{O S L-R}\right)\right)\right)}{(2 \cdot 3)}\right) \\
P_{\text {LTh-peak }}=0.3838 p . u .
\end{gathered}
$$

- $\quad$ Equivalent pre-peak load state $=(0.276)^{0.5}$ p.u. $=0.525$ p.u.

- $\quad$ Transformer peak load state $=(0.3838)^{0.5}$ p.u. $=0.628$ p.u.

- Confidence interval in the determination of the loading state of the transformer using Equation (2), at the peak equal to: 0.009 p.u. 


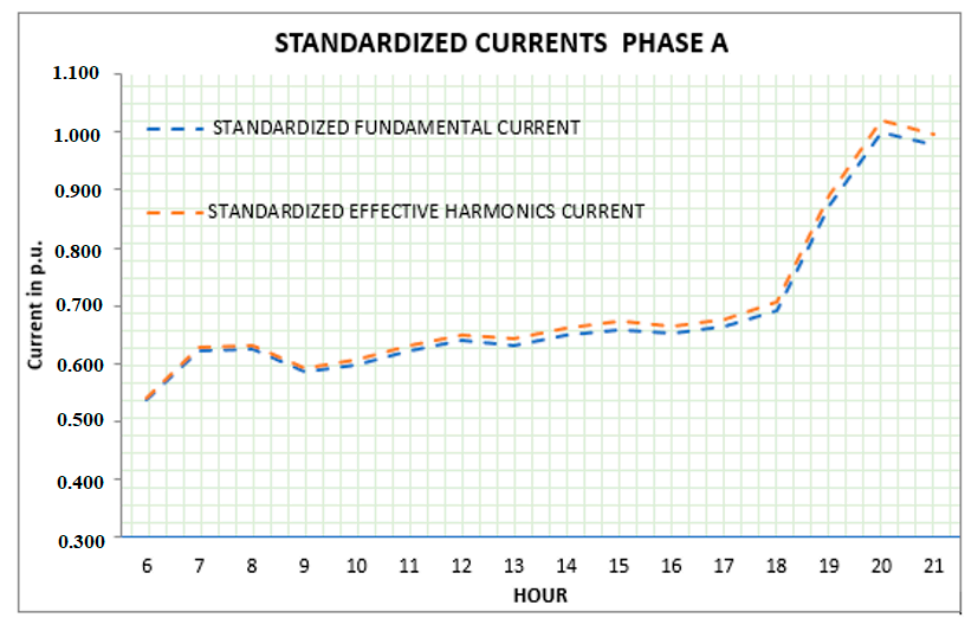

(a). Current daily typical standardized demand graphs for Phase A.

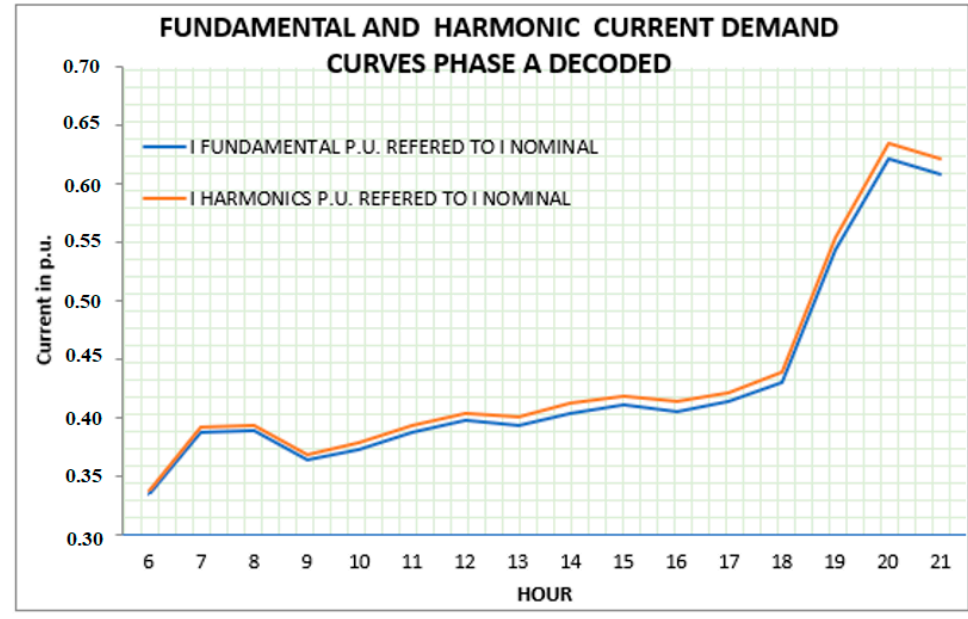

(b). Decoded daily current demand graphs for phase A (p.u. respect to I nominal).

Figure 6. Standardized currents.

In Table $6[4,14,22-28]$ with a $52.5 \%$ pre-peak load state (related to nominal) and extrapolated for three hours and $21{ }^{\circ} \mathrm{C}$ of ambient temperature [29], the transformer should withstand, without reaching the maximum permissible temperature in the hottest point, a $37.2 \%$ overload. The estimated error is in the order of $0.9 \%$. It can be concluded that the safe peak overload limit for this transformer is $36.3 \%$. It is evident that in this case the transformer with a $95 \%$ of confidence level is not in danger of diminishing its operational life span.

\section{Discussion of the Results}

The procedure developed in this research allows the identification of homogeneous groups, which allows, from a database processing of harmonic current measurements in the secondary of single phase distributing transformers, the identification of homogeneous groups of transformers considering the effective harmonics current and harmonic loss factors as normally distributed random variables in each hourly time interval. These results allow obtaining typical daily graphs of average values of effective harmonics current and harmonic loss factors and its confidence intervals.

In accordance with ANSI/IEEE C.57.110 standard, the transformer peak upper load level during a work cycle can be estimated if the harmonic effective currents, harmonic losses factors, and ambient temperature are known. Harmonic effective currents and harmonic losses factors are random variables 
per hour, which is why a deterministic calculation of transformer load state in and hourly interval or duty cycle is not a reliable procedure to its evaluation.

The proposed procedure allows, with simple measurement of transformer fundamental peak current, a reliable calculation of peak upper load level and bounded errors, during a duty cycle of distribution transformers, under the insertion of a discrete number of a new type of nonlinear load which changes daily demand graphs, considering harmonic effective currents and harmonic losses factors as hourly random variables.

Once the homogeneous group to which transformer belongs, the ambient temperature, and fundamental peak current are known, it is possible to obtain a reliable evaluation of the maximum overload that the transformer can allow without breaking the regulations to preserve its operational life span. The results above are essential to determine when it is necessary to replace distribution single phase transformers in any feeder. In the same way, under procedures' assumptions fulfillment, it is possible to project to the future.

\section{Conclusions}

The present work presents a procedure to evaluate overheating related to the insertion in distribution transformers of a new type of load which changes typical demand graph. The evaluation considers the effective harmonics current and harmonic loss factors as normally distributed random variables in each hourly time interval. The procedure presupposes the possible identification of homogeneous groups of transformers considering the effective harmonics current and harmonic loss factors as normally distributed random variables in each hourly time interval to obtain typical daily graphs of average values of effective harmonics current and harmonic loss factors and its confidence intervals. With this information and applying the standard ANSI/IEEE C.57.110, a simple measure of fundamental peak current permits a reliable evaluation of the peak upper load level and its bounded errors, during a duty cycle of distribution transformers in order to reduce the risk of thermal isolation damage.

The developed procedure allows the estimation of the effect that causes in a load cycle, the introduction of a type of polluting load in the heating state of single phase distribution transformers when these loads modify the typical demand graphs, contributing to make decisions about the current and future exploitation of transformers.

The proposed procedure based on a representative database of transformer secondary fundamental and harmonic currents makes possible the estimation of hourly typical harmonic currents and harmonic loss factors graphs. With this information, single measure or estimates of the fundamental peak current permits a reliable estimation of all transformer's loading state and higher bound errors necessary to real time supervision and future secure transformer exploitation.

The application of the methodology to the particular case of Loja city validates the real possibility of its application.

Author Contributions: J.E.C.G., A.M.G., A.d.C.S.; Conceptualization, formal analysis, methodology, analyzed the results and wrote the original manuscript. M.d.C.C.G., R.P.M.V., and K.A.A.C.; validation, writing-review and editing.

Funding: This research received no external funding.

Conflicts of Interest: The authors declare no conflict of interest.

\section{References}

1. IEEE. C57.110-1998-IEEE Recommended Practice for Establishing Transformer Capability When Supplying Non-sinusoidal Load Currentsin; IEEE: Piscataway, NJ, USA, 1998. [CrossRef]

2. Sadati, S.B.; Tahani, A.; Darvishi, B.; Dargahi, M.; Yousefi, H. Comparison of distribution transformer losses and capacity under linear and harmonic loads. In Proceedings of the 2008 IEEE 2nd International Power and Energy Conference, Johor Bahru, Malaysia, 1-3 December 2008; pp. 1265-1269. [CrossRef] 
3. IEEE. C57.110-1986-IEEE Recommended Practice for Establishing Transformer Capability When Supplying Nonsinusoidal Load Currents; IEEE: Piscataway, NJ, USA, 1998; pp. 1-16. [CrossRef]

4. IEEE. C57.110-2008-IEEE Recommended Practice for Establishing Liquid-Immersed and Dry-Type Power and Distribution Transformer Capability When Supplying Nonsinusoidal Load Currents; IEEE: Piscataway, NJ, USA, 2008; pp. 1-68. [CrossRef]

5. Delaiba, A.C.; de Oliveira, J.C.; Vilaca, A.L.A.; Cardoso, J.R. The effect of harmonics on power transformers loss of life. In Proceedings of the 38th Midwest Symposium on Circuits and Systems, Rio de Janeiro, Brazil, 13-16 August 1995; Volume 2, pp. 933-936. [CrossRef]

6. Gómez-Sarduy, J.; Quispe, E.; Reyes-Calvo, R.; Sousa-Santos, V.; Viego-Felipe, P. Influencia de los armónicos de corriente sobre las pérdidas en los transformadores de distribución monofásicos con derivación central. El hombre y la Máquina 2014, 45, 33-43.

7. Elmoudi, A.; Lehtonen, M.; Nordman, H. Effect of harmonics on transformers loss of life. In Proceedings of the 2006 IEEE International Symposium on Electrical Insulation, Toronto, ON, Canada, 11-14 June 2006; pp. 408-411. [CrossRef]

8. Makarov, S.N.; Emanuel, A.E. Corrected harmonic loss factor for transformers supplying nonsinusoidal load currents. In Proceedings of the Ninth International Conference on Harmonics and Quality of Power. Proceedings (Cat. No.00EX441), Orlando, FL, USA, 1-4 October 2000; Volume 1, pp. 87-90. [CrossRef]

9. Walpole, R.E. Probabilidad y Estadística Para Ingeniería y Ciencias, 9th ed.; TX: Naucalpan de Juárez, México, 2012; pp. 172-174.

10. Said, D.M.; Nor, K.M. Effects of harmonics on distribution transformers. In Proceedings of the 2008 Australasian Universities Power Engineering Conference, Sydney, Australia, 14-17 December 2008; pp. 1-5.

11. Abdelsamad, S.F.; Morsi, W.G.; Sidhu, T.S. Probabilistic Impact of Transportation Electrification on the Loss-of-Life of Distribution Transformers in the Presence of Rooftop Solar Photovoltaic. IEEE Trans. Sustain. Energy 2015, 6, 1565-1573. [CrossRef]

12. Stahlhut, J.W.; Heydt, G.T.; Selover, N.J. A Preliminary Assessment of the Impact of Ambient Temperature Rise on Distribution Transformer Loss of Life. IEEE Trans. Power Deliv. 2008, 23, 2000-2007. [CrossRef]

13. Henderson, R.D.; Rose, P.J. Harmonics: The effects on power quality and transformers. IEEE Trans. Ind. Appl. 1994, 30, 528-532. [CrossRef]

14. Amoda, O.A.; Tylavsky, D.J.; McCulla, G.A.; Knuth, W.A. Acceptability of Three Transformer Hottest-Spot Temperature Models. IEEE Trans. Power Deliv. 2011, 27, 13-22. [CrossRef]

15. Daghrah, M.; Wang, Z.D.; Liu, Q.; Walker, D.; Krause, C.; Wilson, G. Experimental investigation of hot spot factor for assessing hot spot temperature in transformers. In Proceedings of the 2016 International Conference on Condition Monitoring and Diagnosis (CMD), Xi'an, China, 25-28 September 2016; pp. $948-951$. [CrossRef]

16. Westinghouse. Electric Utility Engineering Reference Book Distribution Systems; Westinghouse: Pittsburgh, PA, USA, 1965; pp. 35-36.

17. Gonen, T. Electric Power Distribution Engineering, 3rd ed.; CRC Press: Boca Raton, FL, USA, 2014; Volume 4, pp. 100-102.

18. Murray, R.S.; Larry, J.S. Estadistica Shaum, 4th ed.; MC GRAW GRILL: Mexico City, Mexico, 2004; Volume 3, pp. 94-97.

19. Massey, G.W. Estimation methods for power system harmonic effects on power distribution transformers. IEEE Trans. Ind. Appl. 1994, 30, 485-489. [CrossRef]

20. Taheri, S.; Taheri, H.; Fofana, I.; Hemmatjou, H.; Gholami, A. Effect of power system harmonics on transformer loading capability and hot spot temperature. In Proceedings of the 2012 25th IEEE Canadian Conference on Electrical and Computer Engineering (CCECE), Montreal, QC, Canada, 29 April-2 May 2012; pp. 1-4. [CrossRef]

21. El-Bataway, S.A.; Morsi, W.G. Distribution Transformer's Loss of Life Considering Residential Prosumers Owning Solar Shingles, High-Power Fast Chargers and Second-Generation Battery Energy Storage. IEEE Trans. Ind. Inform. 2018, 15, 1287-1297. [CrossRef]

22. Laborí, S.L. Sistemas Eléctricos de Distribución; Universidad Tecnológica de La Habana: Havana, Cuba, 2010; pp. 513-516. 
23. Najdenkoski, K.; Rafajlovski, G.; Dimcev, V. Thermal Aging of Distribution Transformers According to IEEE and IEC Standards. In Proceedings of the 2007 IEEE Power Engineering Society General Meeting, Tampa, FL, USA, 24-28 June 2007; pp. 1-5. [CrossRef]

24. Dao, T.; Phung, B.T. Study of voltage harmonic effect on temperature rise in distribution transformer. In Proceedings of the 2016 IEEE International Conference on Power System Technology (POWERCON), Wollongong, Australia, 28 September-1 October 2016; pp. 1-5. [CrossRef]

25. Dao, T.; Phung, B.T.; Blackburn, T. Effects of voltage harmonics on distribution transformer losses. In Proceedings of the 2015 IEEE PES Asia-Pacific Power and Energy Engineering Conference (APPEEC), Brisbane, Australia, 15-18 November 2015; pp. 1-5. [CrossRef]

26. Awadallah, M.A.; Xu, T.; Venkatesh, B.; Singh, B.N. On the Effects of Solar Panels on Distribution Transformers. IEEE Trans. Power Deliv. 2015, 31, 1176-1185. [CrossRef]

27. IEEE. C57.12.00-2010 IEEE Draft Standard for General Requirements for Liquid-Immersed Distribution, Power, and Regulating Transformers; IEEE: Piscataway, NJ, USA, 2015; pp. 1-71. [CrossRef]

28. López, J.C.; Rider, M.J.; Wu, Q. Parsimonious Short-Term Load Forecasting for Optimal Operation Planning of Electrical Distribution Systems. IEEE Trans. Power Syst. 2019, 34, 1427-1437. [CrossRef]

29. de Loja, M. Perspectivas del Medio Ambiente Urbano: GEO Loja; Programa de las Naciones Unidas para el Medio Programa de las Naciones Unidas para el Medio Ambientë, Loja, Ecuador: Loja, Ecuador, 2007.

(C) 2019 by the authors. Licensee MDPI, Basel, Switzerland. This article is an open access article distributed under the terms and conditions of the Creative Commons Attribution (CC BY) license (http://creativecommons.org/licenses/by/4.0/). 